\title{
Impact of an emergency department opioid prescribing guideline on emergency physician behaviour and incidence of overdose in the Saskatoon Health Region: a retrospective pre-post implementation analysis
}

\author{
Riley J. Hartmann MSc MD, Jeffrey D. Elder MD, Luke A. Terrett MD
}

Abstract

Background: Deaths related to opioid overdoses are increasing in North America, with the emergency department being identified as a potential contributor toward this epidemic. Our goal was to determine whether a departmental guideline for the prescribing of restricted medications resulted in a reduction in opioids prescribed in a Canadian setting, with a secondary objective of determining the impact on local overdose frequency.

Methods: We conducted a retrospective analysis of the prescribing habits of emergency department physicians in 3 hospitals in the Saskatoon Health Region, Saskatchewan, before (Nov. 1, 2015, to Apr. 30, 2016) and after (Nov. 1, 2016, to Apr. 30, 2017) implementation of a guideline in September 2016 for the prescribing of restricted medications. We quantified opioids prescribed per hour worked and per patient seen. We performed Student paired 2-tailed $t$ tests for both individual drug formulations and the combined total morphine equivalents.

Results: Thirty-two emergency department physicians were included. We found a decrease of $31.1 \%$ in opioids prescribed, from 10.36 morphine milligram equivalents (MME) per patient seen to $7.14 \mathrm{MME}$ per patient seen (absolute change $-3.22 \mathrm{MME}$, 95\% confidence interval -4.81 to $-1.63 \mathrm{MME}$ ). Over the same period, we found no change in prehospital naloxone use and a modest increase in the amount of naloxone dispensed by emergency department pharmacies. There was no decrease in the number of overdoses after guideline implementation.

Interpretation: Implementation of a guideline for the prescribing of restricted medications in a Canadian emergency department setting was associated with a decrease in the quantity of opioids prescribed but not in the number of overdoses. This finding suggests that the emergency department is unlikely the source of opioids used in acute overdose, although emergency department opioid prescriptions cannot be ruled out as a risk factor for opioid use disorder.

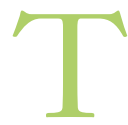

he number of deaths related to opioid overdose has increased substantially in North America over the past decade. ${ }^{1,2}$ In British Columbia, there were 374 fentanyl-related overdose deaths between January and October 2016, an increase of $194 \%$ over the same period in $2015 .^{3}$ Acute care centres and emergency departments have been proposed as potential drivers of this epidemic, ${ }^{4-7}$ including in a recent longitudinal study in Ontario that showed that patients who received opioid prescriptions in the emergency department had a higher risk of admission for opioid toxicity over 2 years. ${ }^{5}$ With its high patient volume and lack of a preexisting patientprovider relationship, the emergency department has been identified as a possible location where opioid use disorders may develop, with upward of $29 \%$ of those misusing opioids having been initially exposed in this setting. ${ }^{5-7}$ The number of opioids prescribed during emergency depart- ment visits in the United States rose substantially over 2001-2010 and continues to trend upward. ${ }^{8}$

The increase in opioid prescriptions has been attributed to numerous factors including aggressive marketing by pharmaceutical companies, the desire to minimize acute and chronic pain, and a lack of discussion between prescribers and patients

Competing interests: Luke Terrett is the creator of the Saskatoon Health Region emergency department guideline for the prescribing of restricted medications. He received no additional funding for his role in the development and implementation of the guideline. No other competing interests were declared.

This article has been peer reviewed.

Correspondence to: Riley Hartmann, rjh110@mail.usask.ca

CMAJ Open 2021. DOI:10.9778/cmajo.20200071 
on the risk of opioid use disorder. ${ }^{9-11}$ As such, clinical policies have been created to target opioid prescribing in US emergency departments. ${ }^{4,12-14}$ Although these policies have been successful in decreasing the number of prescriptions, they have failed to investigate whether the decreased prescription volume results in a decrease in opioid misuse in the community, and have yet to be studied in the Canadian health care system.

The opioid epidemic has resulted in provincial and national changes in prescribing policy, and a shift in attitude of both the general public and the medical community on the risks of opioids. In May 2017, an updated guideline to inform the prescribing of opioids for adults with chronic noncancer pain was released. ${ }^{15}$ The guideline is meant to assist physicians with their prescribing habits and combat the opioid epidemic. Although the guideline provides broad recommendations on prescribing, it was not intended primarily for use in the emergency department.

In September 2016, the Saskatoon Health Region Department of Emergency Medicine updated its prescribing policies for restricted medications. In this study, we sought to determine whether this departmental guideline would result in a reduction in opioid prescriptions and total morphine equivalents (TMEs) prescribed in a Canadian setting. A secondary objective was to examine trends in local overdoses to determine whether the emergency department was a major source of opioids used in these cases.

\section{Methods}

\section{Study design}

We conducted a retrospective pre-post analysis of opioid prescribing patterns in the periods Nov. 1, 2015, to Apr. 30, 2016 (before implementation of the local guideline) and Nov. 1, 2016, and Apr. 30, 2017 (after guideline implementation) among emergency department staff physicians using an existing provincial prescription monitoring program. We also performed a retrospective pre-post analysis of regional naloxone use and emergency department opioid overdose rates to identify potential impacts on local overdose patterns. We used the SQUIRE reporting guidelines for quality-improvement projects. ${ }^{16}$

\section{Setting}

The study was performed in an urban hospital system in the Saskatoon Health Region consisting of 3 emergency departments (Royal University Hospital, St. Paul's Hospital and City Hospital), with total annual patient visits averaging 115000 per year across the system. The region is serviced by a single prehospital emergency medical service provider.

\section{Participants}

Emergency department staff physicians were included if they held part-time or full-time positions throughout the entire study period. For physicians to act as their own control, we excluded those who did not work during either part of the study period; this helped eliminate possible patient selection bias or trading of shifts at certain hours or locations in the city. Overall, this reduced the potential bias that can occur based on diurnal variation in patient characteristics throughout the day. All physicians worked all emergency department shifts (day and night, weekday and weekend) within the region.

\section{Guideline design and implementation}

The guideline for the prescribing of restricted medications in the emergency department was created by an emergency physician (L.A.T.) based on American Society of Interventional Pain Physicians and Canadian guidelines. ${ }^{17,18}$ The guideline was reviewed by an addictions specialist, a family physician and the emergency department head. The guideline sought to encourage physicians to review the patient's prescription history, looking for misuse and diversion when requesting high-risk medications, to contact the patient's primary care provider, to limit the amount of medication prescribed to the next business day, and to reinforce the necessity of a single outpatient prescriber.

The guideline was implemented in September 2016. It was disseminated via email to all Saskatoon Health Region fulltime, part-time and casual emergency department physicians, and was presented and distributed at the monthly emergency department physician staff meeting. A detailed version of the current guideline can be found in Appendix 1 (available at www.cmajopen.ca/content/9/1/E79/suppl/DC1). The guideline was not previously tested or piloted.

\section{Data sources}

We obtained the prescribing histories of the emergency department physicians through the College of Physicians and Surgeons of Saskatchewan Prescription Review Program. The program reviews and identifies prescriptions for high-risk medications, including opioids, stimulants and benzodiazepines, to identify inappropriate medication prescribing, doubledoctoring or inappropriate medication use.

The amount of immediate-release hydromorphone, extendedrelease hydromorphone, immediate-release morphine, sustainedreleased morphine, acetaminophen with codeine and caffeine, acetaminophen with oxycodone, fentanyl (in patches), gabapentin and pregabalin prescribed by individual physicians over the study period was extracted from the provincial Pharmaceutical Information Program database by a designate within the Prescription Review Program. The Pharmaceutical Information Program is a provincial database of all prescriptions dispensed to Saskatchewan residents that is maintained by the Ministry of Health. All outpatient pharmacies are provincially mandated to ensure prescribing information is uploaded to the database for each patientprescription pairing, and are responsible for the completeness, timeliness and accuracy of the information. All data entered into the Pharmaceutical Information Program are tracked and logged for audit purposes. The Pharmaceutical Information Program database is used throughout the province as the most reliable data regarding patient prescription histories. ${ }^{19,20}$

We converted all medications to TMEs using the conversion ratios from the 2017 Canadian guideline for opioid therapy and chronic noncancer pain ${ }^{15}$ to allow for comparison between formulations. The number of hours worked was extracted from the department's physician scheduling program, and the number of patients seen by each physician was taken from data 
collected within the electronic health record based on patients assigned to each physician. The hours worked and patients seen were provided to the Prescription Review Program, who returned the pseudonymized prescription data found in Appendix 2 (available at www.cmajopen.ca/content/9/1/E79/suppl/ DC1). As fentanyl patches were infrequently prescribed and were likely a refill on a long-term prescription until a primary care provider could be seen, we removed these data from the overall analysis. The numbers of gabapentin and pregabalin prescriptions were too small to permit any conclusions to be drawn, and these drugs were also excluded from analysis.

We then divided TMEs prescribed by total hours worked and total patients seen for each physician in order to compare prescribing rates between physicians. Standardizing our outcomes on both per hour worked and per patient seen allowed us to take into account practice variability between physicians who see more or fewer patients in a given shift, as well as physicians who work less than full time in the emergency department. This ultimately allowed comparison of TMEs prescribed between physicians, accounting for physician speed and number of shifts worked.

We collected data on naloxone use from the emergency medical service provider (Medavie Health Services West) and the emergency department pharmacies in the Saskatoon Health Region.

The Saskatoon Health Region Public Health Observatory Sentinel Opioid Overdose Surveillance Group began collecting data prospectively in May 2017 to track opioid overdose rates within the Saskatoon Health Region. Ambulance, police and pharmacy data are uploaded or emailed weekly to the Public Health Observatory. Uncoded "real-time" emergency department data based on reason for presentation to the emergency department and emergency department physician International Classification of Diseases, 9th Revision (ICD-9) ${ }^{21}$ or International Statistical Classification of Diseases and Related Health Problems, 10th Revision (ICD-10) ${ }^{22}$ discharge diagnosis codes are received electronically.

We analyzed emergency department data retrospectively to 2016. Coded data (based on nationally recommended Tcodes and $\mathrm{F} 11^{11,22}$ ) are received up to 6 months later and complement the "real-time" uncoded emergency department data. Uncoded data labelled "emergency department overdose high risk/ unknown substance" and "emergency department substance misuse" (Canadian Triage and Acuity Scale levels 1-3) generally correspond with coded emergency department data in our data set. Coded opioid overdose deaths included only those of patients who were declared deceased in hospital. These data were provided by the Public Health Observatory. Owing to a paucity of data before guideline implementation, we did not have sufficient data to estimate a reliable slope; instead, we analyzed the data visually for a trend after guideline implementation.

\section{Statistical analysis}

We totalled the amounts of drugs for individual physicians and compared them between the pre- and postimplementation study periods. We performed Student paired 2-tailed $t$ tests for individual drug formulations and the combined TMEs, for the pre- and postimplementation periods. All physicians included in the study were present for both the pre- and postimplementation periods and served as their own controls. We calculated standard deviations and $95 \%$ confidence intervals (CIs).

\section{Ethics approval}

This study was deemed exempt from ethics review by the University of Saskatchewan and the Saskatoon Health Region research ethics boards (REB BIO no. 17-118).

\section{Results}

A total of 34 physicians were identified, of whom 2 were excluded because they worked only a single part of the study period. Demographic characteristics of the 32 physicians are given in Table 1.

The average amount of opioids prescribed per hour decreased by $28.6 \%$ after implementation of the prescribing guideline, from 18.51 morphine milligram equivalents (MME) to 13.22 MME (absolute change -5.29 MME, 95\% CI -7.60 to -2.97 MME) (Table 2). The average amount prescribed per patient seen decreased by $31.1 \%$, from 10.36 MME to 7.14 MME (absolute change -3.22 MME, 95\% CI -4.81 to $-1.63 \mathrm{MME}$ ) (Table 3 ).

\begin{tabular}{|c|c|}
\hline Characteristic & $\begin{array}{c}\text { No. }(\%) \text { of physicians }{ }^{*} \\
n=32\end{array}$ \\
\hline \multicolumn{2}{|l|}{ Gender } \\
\hline Male & $25(78)$ \\
\hline Female & $7(22)$ \\
\hline \multicolumn{2}{|l|}{ Certification } \\
\hline CCFP & $8(25)$ \\
\hline CCFP-EM & $18(56)$ \\
\hline FRCPC-EM & $4(12)$ \\
\hline Other & $2(6)$ \\
\hline Average years in practice (range) & 12.66 (0 to 40$)$ \\
\hline \multicolumn{2}{|l|}{ Average no. of patients seen (range) } \\
\hline Before guideline implementation $†$ & 980.2 (244 to 2145 ) \\
\hline After guideline implementation $\ddagger$ & 912.7 (136 to 2272 ) \\
\hline \multicolumn{2}{|l|}{ Average hours worked (range) } \\
\hline Before guideline implementation $†$ & $536.33(136.00$ to 966.50$)$ \\
\hline After guideline implementation $\ddagger$ & 494.26 (87.25 to 993.25$)$ \\
\hline \multicolumn{2}{|l|}{ Average no. of patients per hour (range) } \\
\hline Before guideline implementation $\dagger$ & $1.84(1.12$ to 2.46$)$ \\
\hline After guideline implementation $\ddagger$ & $1.84(1.45$ to 2.29$)$ \\
\hline \multicolumn{2}{|c|}{$\begin{array}{l}\text { Note: CCFP = Canadian College of Family Physicians, CCFP-EM = Canadian } \\
\text { College of Family Physicians Emergency Medicine Certification, FRCPC-EM = } \\
\text { Fellow of the Royal College of Physicians of Canada in Emergency Medicine. } \\
\text { *Unless stated otherwise. } \\
\text { †Nov. } 1,2015, \text { to Apr. } 30,2016 \text {. } \\
\ddagger \text { Nov. } 1,2016 \text {, to Apr. 30, } 2017 \text {. }\end{array}$} \\
\hline
\end{tabular}




\begin{tabular}{|c|c|c|c|c|c|}
\hline \multirow[b]{2}{*}{ Drug } & \multicolumn{2}{|c|}{$\begin{array}{c}\text { Before guideline } \\
\text { implementation, MME }\end{array}$} & \multicolumn{2}{|c|}{$\begin{array}{c}\text { After guideline } \\
\text { implementation, MME }\end{array}$} & \multirow{2}{*}{$\begin{array}{l}\text { Average reduction } \\
(95 \% \mathrm{Cl})\end{array}$} \\
\hline & Average & Median & Average & Median & \\
\hline Hydromorphone IR & 12.44 & 10.91 & 8.56 & 6.59 & $-3.88(-5.70$ to -2.05$)$ \\
\hline Hydromorphone ER & 1.66 & 0.63 & 0.98 & 0.00 & $-0.68(-1.45$ to 0.09$)$ \\
\hline Morphine IR & 0.85 & 0.54 & 0.72 & 0.42 & $-0.13(-0.43$ to 0.19$)$ \\
\hline Morphine SR & 0.65 & 0.00 & 0.26 & 0.00 & $-0.39(-1.17$ to 0.38$)$ \\
\hline $\begin{array}{l}\text { Oxycodone + acetaminophen } \\
\text { tablets }\end{array}$ & 0.07 & 0.00 & 0.08 & 0.00 & $0.01(-0.10$ to 0.13$)$ \\
\hline $\begin{array}{l}\text { Acetaminophen }+ \text { caffeine } \\
+ \text { codeine tablets }\end{array}$ & 2.84 & 2.08 & 2.62 & 1.72 & $-0.22(-0.95$ to 0.52$)$ \\
\hline Total & 18.51 & 16.07 & 13.22 & 11.22 & $-5.29(-7.60$ to -2.97$)$ \\
\hline
\end{tabular}

\begin{tabular}{|c|c|c|c|c|c|}
\hline \multirow[b]{2}{*}{ Drug } & \multicolumn{2}{|c|}{$\begin{array}{c}\text { Before guideline } \\
\text { implementation, MME }\end{array}$} & \multicolumn{2}{|c|}{$\begin{array}{c}\text { After guideline } \\
\text { implementation, MME }\end{array}$} & \multirow{2}{*}{$\begin{array}{l}\text { Average reduction } \\
\qquad(95 \% \mathrm{Cl})\end{array}$} \\
\hline & Average & Median & Average & Median & \\
\hline Hydromorphone IR & 6.84 & 6.24 & 4.62 & 4.14 & $-2.22(-3.27$ to -1.17$)$ \\
\hline Hydromorphone ER & 1.00 & 0.32 & 0.53 & 0.00 & $-0.47(-0.97$ to 0.04$)$ \\
\hline Morphine IR & 0.46 & 0.28 & 0.40 & 0.24 & $-0.06(-0.23$ to 0.11$)$ \\
\hline Morphine SR & 0.36 & 0.00 & 0.16 & 0.00 & $-0.20(-0.66$ to 0.25$)$ \\
\hline $\begin{array}{l}\text { Oxycodone + acetaminophen } \\
\text { tablets }\end{array}$ & 0.06 & 0.00 & 0.04 & 0.00 & $-0.02(-0.10$ to 0.08$)$ \\
\hline $\begin{array}{l}\text { Acetaminophen + caffeine } \\
+ \text { codeine tablets }\end{array}$ & 1.65 & 1.25 & 1.39 & 0.99 & $-0.26(-0.66$ to 0.14$)$ \\
\hline Total & 10.36 & 8.86 & 7.14 & 6.18 & $-3.22(-4.81$ to -1.63$)$ \\
\hline
\end{tabular}

There was a decrease of $31.2 \%$ in the average amount of opioids prescribed per hour for immediate-release hydromorphone, from 12.44 MME to 8.56 MME (absolute change $-3.88 \mathrm{MME}, 95 \% \mathrm{CI}-5.70$ to $-2.05 \mathrm{MME}$ ), and a decrease in the average amount prescribed per patient seen of $32.5 \%$, from 6.84 MME to 4.62 MME (absolute change $-2.22 \mathrm{MME}, 95 \% \mathrm{CI}-3.27$ to $-1.17 \mathrm{MME}$ ). The average amount prescribed for the other types of opioids did not change ( $p>0.05$ for all). The raw individual prescriber data before and after guideline implementation are presented in Appendix 2.

The individual prescriber distribution of TMEs prescribed before and after guideline implementation is presented in Figure 1 , and the distributions by specific opioids are given in Appendix 3 (available at www.cmajopen.ca/content/9/1/E79/ suppl/DC1). Overall, we found decreased variation between physicians after guideline implementation, with a decrease in the median, the mean and the third quartiles.
Prehospital and emergency department use of naloxone is shown in Table 4. The number of patients treated with naloxone before and after guideline implementation was the same (39). The number of vials of naloxone $(2 \mathrm{mg} / 2 \mathrm{~mL})$ dispensed by the 3 emergency departments increased from 164 before guideline implementation to 174 after implementation.

There was no observed decrease in opioid overdoses or high-risk substances presenting to the 3 emergency departments after guideline implementation (Figure 2); however, this observation is limited owing to a lack of data before guideline implementation.

\section{Interpretation}

Implementation of a guideline for the prescribing of restricted medications in a Canadian emergency department was associated with a decrease of $31 \%$ in opioids prescribed. Over the same period, we found no change in emergency medical 
A

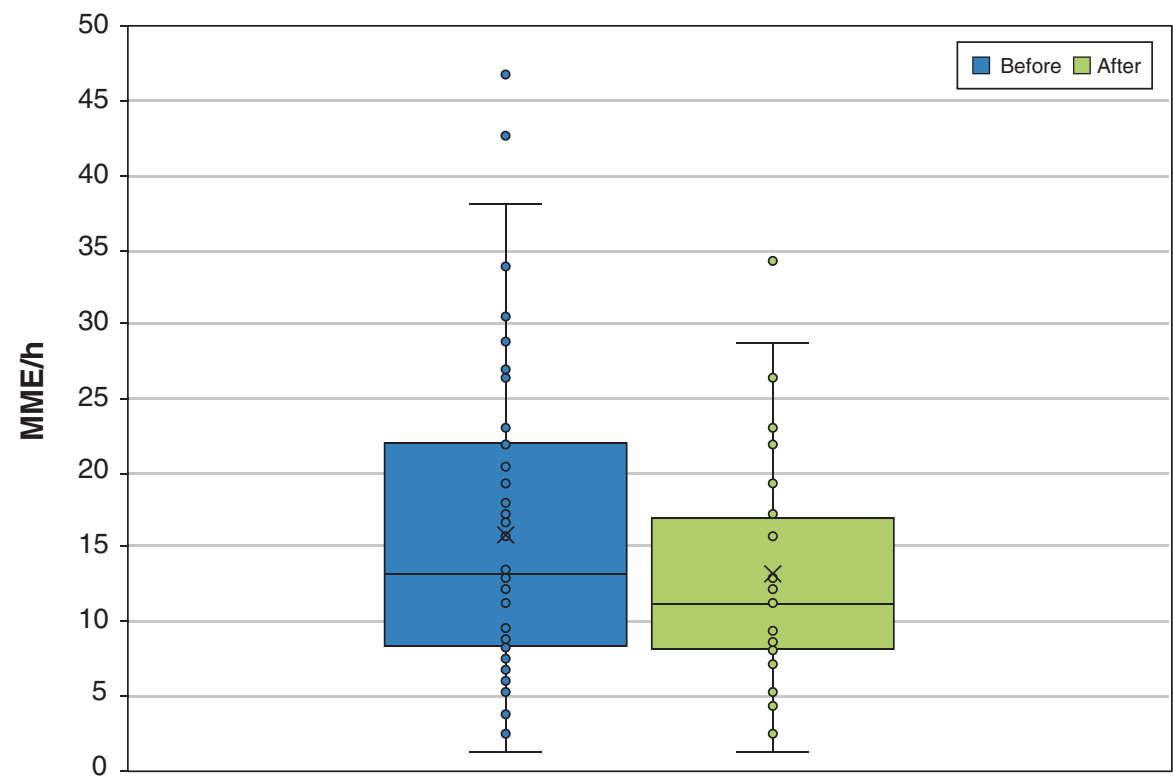

B

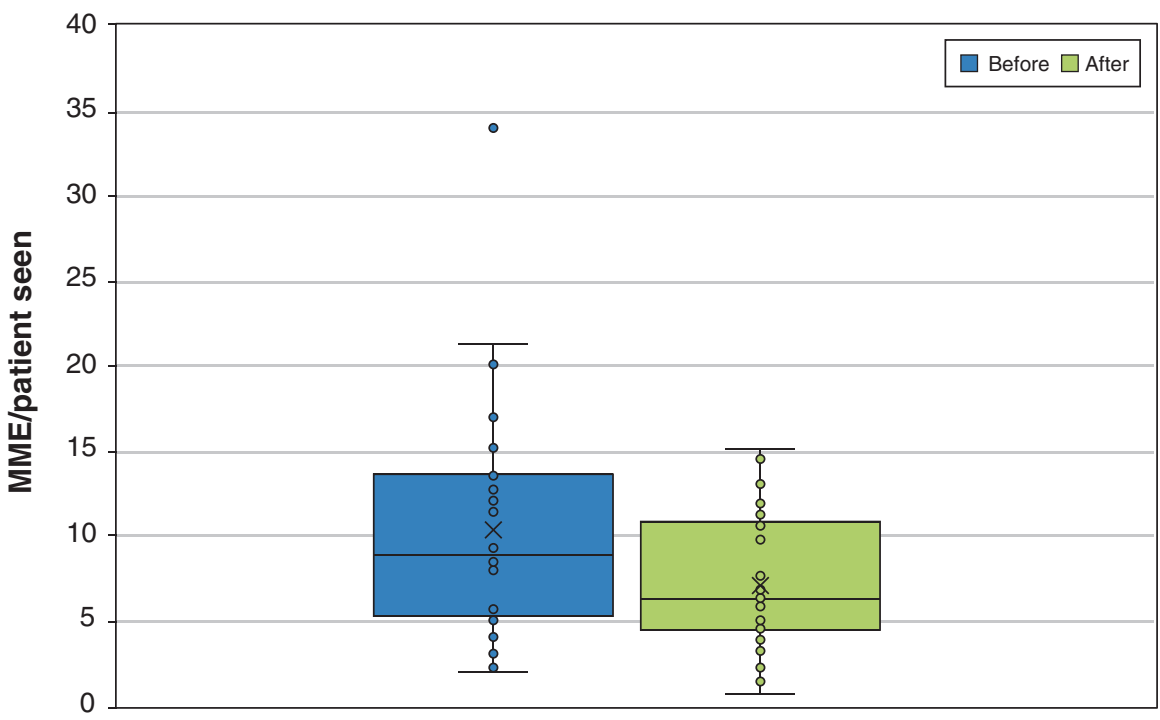

Figure 1: Prescriber distribution of total morphine equivalents prescribed per hour worked $(\mathrm{A})$ and per patient seen (B). Error bars represent standard deviation; $\times$ represents mean. Note: MME = morphine milligram equivalent.

service use of naloxone, a modest increase in the amount of naloxone dispensed by emergency department pharmacies, and no change in the number of overdoses in the health region. The reason for these latter findings may be twofold. First, patients who overdose on opioids may have acquired their narcotics from sources other than the emergency department, whether prescription or elicit. Second, the initiation of opioid treatment in the emergency department has been implicated as a risk factor for opioid use disorder and overdose. ${ }^{4-7}$ Given our observed reduction of TMEs prescribed of nearly one-third, the effects of reducing the number of patients exposed to opioids could take several years to manifest. 
Similar studies have been conducted in the US, 4,14 although the investigators looked only at a specific ICD-9 diagnosis or excluded some emergency department providers.

\begin{tabular}{|c|c|c|}
\hline Variable & $\begin{array}{l}\text { Before guideline } \\
\text { implementation }\end{array}$ & $\begin{array}{l}\text { After guideline } \\
\text { implementation }\end{array}$ \\
\hline \multicolumn{3}{|c|}{ Prehospital naloxone given by EMS } \\
\hline No. of patients treated & 39 & 39 \\
\hline Total drug administered, mg & 23.4 & 34.5 \\
\hline $\begin{array}{l}\text { No. of naloxone vials* } \\
\text { dispensed to emergency } \\
\text { departments }\end{array}$ & 164 & 174 \\
\hline Emergency department 1 & 10 & 1 \\
\hline Emergency department 2 & 111 & 134 \\
\hline Emergency department 3 & 43 & 39 \\
\hline
\end{tabular}

Moreover, they evaluated only the number of prescriptions and not the quantity of TMEs prescribed, and neither study assessed the impact of a guideline for the prescribing of restricted medications on the incidence of overdose in the community. Weiner and colleagues ${ }^{4}$ found that emergencydepartment-specific guidelines reduced the number of opioid prescriptions issued by emergency department physicians by $12 \%$. The Saskatoon Health Region emergency department guideline for the prescribing of restricted medications used similar recommendations and was associated with a reduction of $31.1 \%$ in TMEs prescribed, driven entirely by a decrease in prescribing of immediate-release hydromorphone. That immediate-release hydromorphone was the main driver for the decrease is likely due to local practice, wherein immediate-release hydromorphone accounted for $66 \%$ of all opioid prescriptions from our emergency departments during the study period (Appendix 2).

\section{Limitations}

The emergency department prescribing guideline was not tested before implementation. In addition, we cannot know whether the guideline was the sole driver of practice change. Local and national attitudes and culture have been shifting,

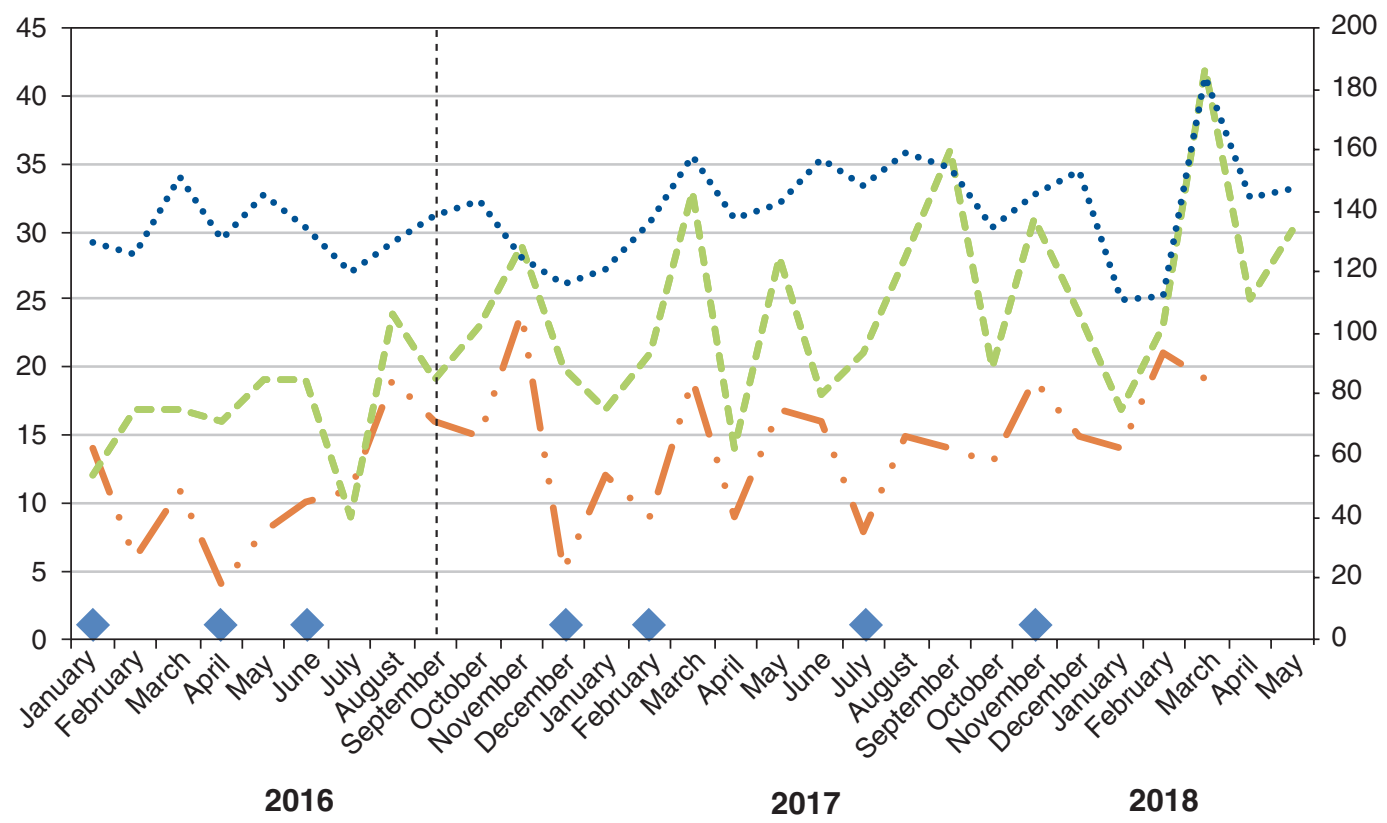

\begin{tabular}{|c|c|}
\hline $\begin{array}{cl}- & \text { ED overdose high-risk/unknown substance } \\
\text { Coded opioid overdose death } \dagger\end{array}$ & $\begin{array}{l}\text { —... Coded ED opioid overdose* } \\
\text {....... ED substance misuse }\end{array}$ \\
\hline
\end{tabular}

Figure 2: Cases of opioid overdose, overdose from high-risk or unknown substances, and opioid misuse presenting to the 3 emergency departments (EDs) in the Saskatoon Health Region from January 2016 to May 2018, along with deaths from opioid overdose. Vertical dashed line denotes implementation of ED guideline for prescribing of restricted medications. ${ }^{*}$ Tcodes and F11. †Includes deaths occurring in hospital only. $\ddagger$ Canadian Triage and Acuity Scale levels $1-3$. 
and this may account for some of the observed changes in prescribing habits. We also cannot comment on the appropriateness of the opioid prescriptions provided and whether the decrease in TMEs prescribed was due to a decreased frequency of prescriptions or a decrease in the quantity prescribed per prescription; we speculate that it is a combination of the two.

Although the numbers were too small to permit us to draw any conclusions, some physicians may have shifted toward nonopioid alternatives, including gabapentin or pregabalin, over the study period.

The coding of emergency department data in the Saskatoon Health Region is through the emergency department physician's ICD-9 or ICD-10 discharge diagnosis on the electronic chart. As the specific drug overdose, or even diagnosis, is often unclear at the time of discharge from the emergency department or admission to hospital, the emergency department physician's discharge diagnosis is often vague, which makes emergency department overdoses difficult to extract for surveillance of overdose rates. Additional emergency department data are collected through the broad category selected at triage as the reason for presentation, which may miss some overdoses, especially in cases in which respiratory arrest is designated as the most urgent reason. These limitations extend into coded opioid overdose deaths seen in our region, which may have decreased the number of opioid-related deaths documented.

In addition, we were unable to identify any direct associations between emergency department opioid prescriptions and community opioids. Previous investigators linked initiation of opioid treatment in the emergency department to a risk of opioid use disorder later in life. ${ }^{4-7}$ The reasons for this are likely multifactorial, including lack of follow-up and lack of time for patient education.

This study was performed in an emergency department setting, and the findings may not be generalizable to other outpatient or inpatient settings.

Finally, the emergency department pharmacy restocking of naloxone does not necessarily relate directly to naloxone use. Vials may have expired, been opened and not used, broken or been transferred to other units in the hospital. In addition, pharmacy restocking of naloxone in the emergency department is not necessarily done consistently, which may have affected the numbers reported.

\section{Conclusion}

We observed a reduction of $31 \%$ in TMEs of opioids per patient seen after implementation of an emergency department guideline for the prescribing of restricted medications in a Canadian setting. This finding suggests that the emergency department is unlikely the source of opioids used in acute overdose, although emergency department opioid prescriptions cannot be ruled out as a risk factor for opioid use disorder. Further studies are needed to investigate the impact of expanding guidelines for the prescribing of restricted medications to other specialties and settings. In addition, the long-term effects of such a guideline on the incidence of opioid use disorder and misuse in the community needs to be studied further.

\section{References}

1. King NB, Fraser V, Boikos C, et al. Determinants of increased opioid-related mortality in the United States and Canada, 1990-2013: a systematic review. Am 7 Public Health 2014;104:e32-42.

2. Dhalla IA, Mamdani MM, Sivilotti MLA, et al. Prescribing of opioid analgesics and related mortality before and after the introduction of long-acting oxycodone. CMA7 2009;181:891-6.

3. Jafari S, Buxton JA, Joe R. Rising fentanyl-related overdose deaths in British Columbia. Can 7 Addict 2015;6:4-6.

4. Weiner SG, Baker O, Poon SJ, et al. The effect of opioid prescribing guidelines on prescriptions by emergency physicians in Ohio. Ann Emerg Med 2017; 70:799-808.e1.

5. Borgundvaag B, McLeod S, Khuu $W$, et al. Opioid prescribing and adverse events in opioid-naive patients treated by emergency physicians versus family physicians: a population-based cohort study. CMA7 Open 2018;6:E110-7.

6. Hoppe JA, Kim H, Heard K. Association of emergency department opioid initiation with recurrent opioid use. Ann Emerg Med 2015;65:493-9.e4.

7. Butler MM, Ancona RM, Beauchamp GA, et al. Emergency department prescription opioids as an initial exposure preceding addiction. Ann Emerg Med 2016;68:202-8.

8. Mazer-Amirshahi M, Mullins PM, Rasooly I, et al. Rising opioid prescribing in adult U.S. emergency department visits: 2001-2010. Acad Emerg Med 2014;21: 236-43.

9. Okie S. A flood of opioids, a rising tide of deaths. N Engl f Med 2010;363: 1981-5.

10. Porter J, Jick H. Addiction rare in patients treated with narcotics. N Engl $7 \mathrm{Med}$ 1980;302:123

11. The use of opioids for the treatment of chronic pain. A consensus statement from the American Academy of Pain Medicine and the American Pain Society. Clin 7 Pain 1997;13:6-8.

12. Cantrill SV, Brown MD, Carlisle RJ, et al.; American College of Emergency Physicians Opioid Guideline Writing Panel. Clinical policy: critical issues in the prescribing of opioids for adult patients in the emergency department. Ann Emerg Med 2012;60:499-525.

13. Suffoletto B, Lynch M, Pacella CB, et al. The effect of a statewide mandatory prescription drug monitoring program on opioid prescribing by emergency medicine providers across 15 hospitals in a single health system. 7 Pain 2018; 19:430-8.

14. Beaudoin FL, Janicki A, Zhai W, et al. Trends in opioid prescribing before and after implementation of an emergency department opioid prescribing policy. Am 7 Emerg Med 2018;36:329-31.

15. Busse JW, Craigie S, Juurlink DN, et al. Guideline for opioid therapy and chronic noncancer pain. CMAJ 2017;189:E659-66.

16. Ogrinc G, Davies L, Goodman D, et al. Standards for QUality Improvement Reporting Excellence 2.0: revised publication guidelines from a detailed consensus process. 7 Surg Res 2016;200:676-82.

17. Kahan M, Mailis-Gagnon A, Wilson L, et al. Canadian guideline for safe and effective use of opioids for chronic noncancer pain. Part 1: general population. Can Fam Physician 2011;57:1257-66, e407-18.

18. Manchikanti L, Abdi S, Atluri S, et al. American Society of Interventional Pain Physicians (ASIPP) guidelines for responsible opioid prescribing in chronic non-cancer pain: Part 2 - guidance. Pain Physician 2012;15(Suppl): S67-116.

19. PIP desk reference: the Pharmaceutical Information Program. Regina: eHealth Saskatchewan; 2013:1-88. Available: www.ehealthsask.ca/services/pip/Documents/Resources/PIPDeskReference.pdf (accessed 2020 Sept. 14).

20. The Prescription Drugs Act. Chapter P-23 of The Revised Statutes of Saskatchewan, 1978 (effective Feb. 26, 1979) as amended by the Statutes of Saskatchewan, 1979, c.55; 1982-83, c. $16 ; 1983$, c. $29 ; 1986-87-88$, c.54; 1988-89, c.42; 1993, c.57; 1997 , c.12; 2002, c.22; 2004, c.10; 2010, c.27, 2014, c.E-13.1, 2015, c.17; and 2018, c.42. Available: https://publications.saskatchewan.ca/api/v1/products/766/ formats/1170/download (accessed 2020 Sept. 14).

21. International Classification of Diseases, 9th Revision: basic tabulation list with alphabetic index. Geneva: World Health Organization; 1978. Available: https://apps. who.int/iris/handle/10665/39473 (accessed 2020 June 28).

22. International Statistical Classification of Diseases and Related Health Problems: 10th revision. 2nd ed. Geneva: World Health Organization; 2004. Available: https:// apps.who.int/iris/handle/10665/42980 (accessed 2020 June 28).

Affiliations: College of Medicine (Hartmann, Elder) and Department of Emergency Medicine (Hartmann, Elder, Terrett), University of Saskatchewan; Department of Adult Critical Care Medicine (Terrett), Saskatchewan Health Authority, Saskatoon, Sask.

Contributors: Luke Terrett is the lead author. He conceived the work. Luke Terrett and Riley Hartmann designed the study. Riley Hartmann 
and Jeffrey Elder acquired and analyzed the data. All of the authors interpreted the data, drafted the manuscript, approved the final version to be published and agreed to be accountable for all aspects of the work.

Funding: Research funding was provided by an internal grant from the University of Saskatchewan College of Medicine Dean's Project fund awarded to Jeffrey Elder.

Data sharing: Raw data from this study are not available for distribution owing to data-sharing agreements between the authors and the sources of the data.

Content licence: This is an Open Access article distributed in accordance with the terms of the Creative Commons Attribution (CC BY-NC-ND 4.0) licence, which permits use, distribution and reproduction in any medium, provided that the original publication is properly cited, the use is noncommercial (i.e., research or educational use), and no modifications or adaptations are made. See: https://creativecommons.org/licenses/ by-nc-nd/4.0/.

Acknowledgements: The authors thank Leah Heilman for sharing Saskatoon Health Region pharmacy data, Tim Hillier for providing emergency medical service data, Liisa Scherban for extracting provider prescription data and Judith Wright for sharing local Public Health Observatory overdose data.

Supplemental information: For reviewer comments and the original submission of this manuscript, please see www.cmajopen.ca/content/9/1/ E79/supp1/DC1. 